\title{
Effect of Synthesis Temperature on the Growth of Carbon-based Materials from Waste Engine Oil Precursor
}

\author{
Suhufa Alfarisa ${ }^{1 *}$, Suriani Abu Bakar ${ }^{2}$ \\ ${ }^{1}$ Department of Physics, Faculty of Mathematics and Natural Sciences, \\ Universitas PGRI Palembang, Palembang 30251, Indonesia \\ ${ }^{2}$ Department of Physics, Faculty of Science and Mathematics \\ Universiti Pendidikan Sultan Idris, Perak 35900 Malaysia \\ *e-mail: suhufaalfarisa@gmail.com
}

\begin{abstract}
Different stuctures of carbon material were succesfully synthesized from waste engine oil (WEO) as carbon source using double-stage thermal chemical vapor deposition method. In this work, $5.33 \mathrm{wt} \%$ ferrocene was used as catalyst, precursor temperature at $450^{\circ} \mathrm{C}$ and the synthesis temperatures were varied from $600-1000^{\circ} \mathrm{C}$ with $100^{\circ} \mathrm{C}$ increament. The prepared samples were characterized using field emission scanning electron microscopy and microRaman spectroscopy. Below $700^{\circ} \mathrm{C}$, amorphous structure of carbon was formed. Well growth carbon spheres were produced at $800^{\circ} \mathrm{C}$ while at $900^{\circ} \mathrm{C}$, bigger diameter and lower crystallinity of carbon spheres were resulted. At very high temperature, $1000^{\circ} \mathrm{C}$, a highly defective structure of carbon was produced. These results show that the structure of carbon materials from WEO precursor was highly affected by synthesis temperature changes.
\end{abstract}

Keywords: waste engine oil, carbon-based material, thermal chemical vapor deposition

\section{INTRODUCTION}

Carbon is an abundant element in nature and can be formed into many kind of carbon-based materials such as carbon nanofibers, carbon nanotubes (CNTs), carbon black nanoparticle, graphene, conductive carbon, carbon dye, mesoporous carbon (Poudel and Qiao) and carbon spheres (Zobir, Abdullah et al.). These carbon-based materials have many applications in electrical and optical devices such as solar cell (Poudel and Qiao), field electron emission (Asli, Shamsudin et al.), microcable (Shanov, Cho et al. 2013), transistor (Donev 2009), energy storage, filled composites, nanoprobes and sensors (Ajayan and Zhou 2001; Wilgosz, Chen et al. 2012). They also have been applied in sports equipment, automotive and textile (Nowack, David et al. 2013). Because of the great properties and promising applications, the researchers have been intensely studied about these materials since the last two decades.

Several methods have been used to synthesis carbon-based materials, but the use of thermal chemical vapor deposition (TCVD) method is the most popular method among others due to its simplicity, easy to scale up and still produce the high quality products. The selection of carbon precursor becomes very important in carbon-based materials synthesis. Unfortunately, the use of conventional hydrocarbon such as methane, propane, butane, hexane, acetylene and ethylene as carbon sources to produce carbon-based materials are not cost effective due to the expensiveness. We have recently reported the use of waste materials such as waste cooking palm oil (Suriani, Md Nor et al. 2010) waste chicken fat (Suriani, Dalila et al. 2013) and waste engine oil (WEO) to 
produce CNTs (Suriani, Alfarisa et al. 2015; Alfarisa and Suriani 2016).

WEO contains polycyclic aromatic hydrocarbons (PAHs) and metal contaminants that are harmfull for living organisms if not treated properly. We investigated the synthesis temperature changes to the structure, morphology and crystallinity of carbon-based materials from WEO. Previously we reported the effect of catalyst consentrations on the growth of CNTs from WEO (Alfarisa, Safitri et al. 2016). Here, the effect of synthesis temperatures was analyzed on the growth of carbon based materials from WEO precursor.

\section{MATERIALS AND METHOD}

The synthesis of carbon-based materials from waste engine oil was done using double stage TCVD furnace with fixed precursor vaporization temperature at $450^{\circ} \mathrm{C}$ based on thermogravimetric (TGA) analysis in Fig. 1(a). Silicon substrates with $1 \mathrm{~cm}^{2}$ area were ultrasonically cleaned using acetone, methanol and DI water before being used. The substrates were than placed into synthesis furnace and the temperatures were varied from 600 $1000^{\circ} \mathrm{C}$. Waste engine oil was filtered first before being mixed with $5.33 \mathrm{wt} \%$ of ferrocene as catalyst. After stirring for 30 minutes, $3 \mathrm{~mL}$ of the mixture was put in alumina boat and then loaded into precursor furnace. Argon (Ar) gas was flushed out during the first 10 minutes before the synthesis process starts. Precursor furnace was turned on after the synthesis furnace reached the set temperature. The synthesis process lasted for 30 minutes under Ar gas flow. The samples were collected and characterized using field emission scanning electron microscopy (FESEM-Hitachi SU8020) and micro-Raman spectroscopy (Renishaw InVia microRaman System).

\section{RESULTS AND DISCUSSION}

Another parameter conditions other than synthesis temperature were kept fixed in this experiment. Different structures of carbon-based materials at various synthesis temperature from waste engine oil are shown in Fig. 1(b)-(f). When the precursor furnace temperature reach $185^{\circ} \mathrm{C}$, ferrocene molecules start to vaporized (Cheng, Li et al. 1998) and were deposited on the substrate in synthesis area via $\mathrm{Ar}$ gas flow. At synthesis temperatures below $700^{\circ} \mathrm{C}$, amorphous structures of carbon materials were produced. It was assumed that the temperatures were not high enough to completely decompose the precursor and caused the low catalytic activity of $\mathrm{Fe}$ particles. Surprisingly, at $700^{\circ} \mathrm{C}$, a material contained copper $(\mathrm{Cu})$ and aluminum ( $\mathrm{Al}$ ) were produced along with carbon microspheres. It was believed that the natural presence of $\mathrm{Cu}$ and $\mathrm{Al}$ contaminants from WEO during the lubricating process were promoted the growth of this material. When the temperature was increased to $800^{\circ} \mathrm{C}$, high density of carbon microspheres were formed. Diameter of the spheres were range from 0.17-2.57 $\mu \mathrm{m}$. Carbon microspheres with lower crystallinity and bigger size were also produced at $900^{\circ} \mathrm{C}$. The spheres diameter range were from $0.57-3.14 \mu \mathrm{m}$. Larger agglomeration of Fe particles were formed at higher temperature and caused the bigger diameter of carbon microspheres. The changes and destruction of carbon structure was occurred when the temperature was raised to $1000^{\circ} \mathrm{C}$. 

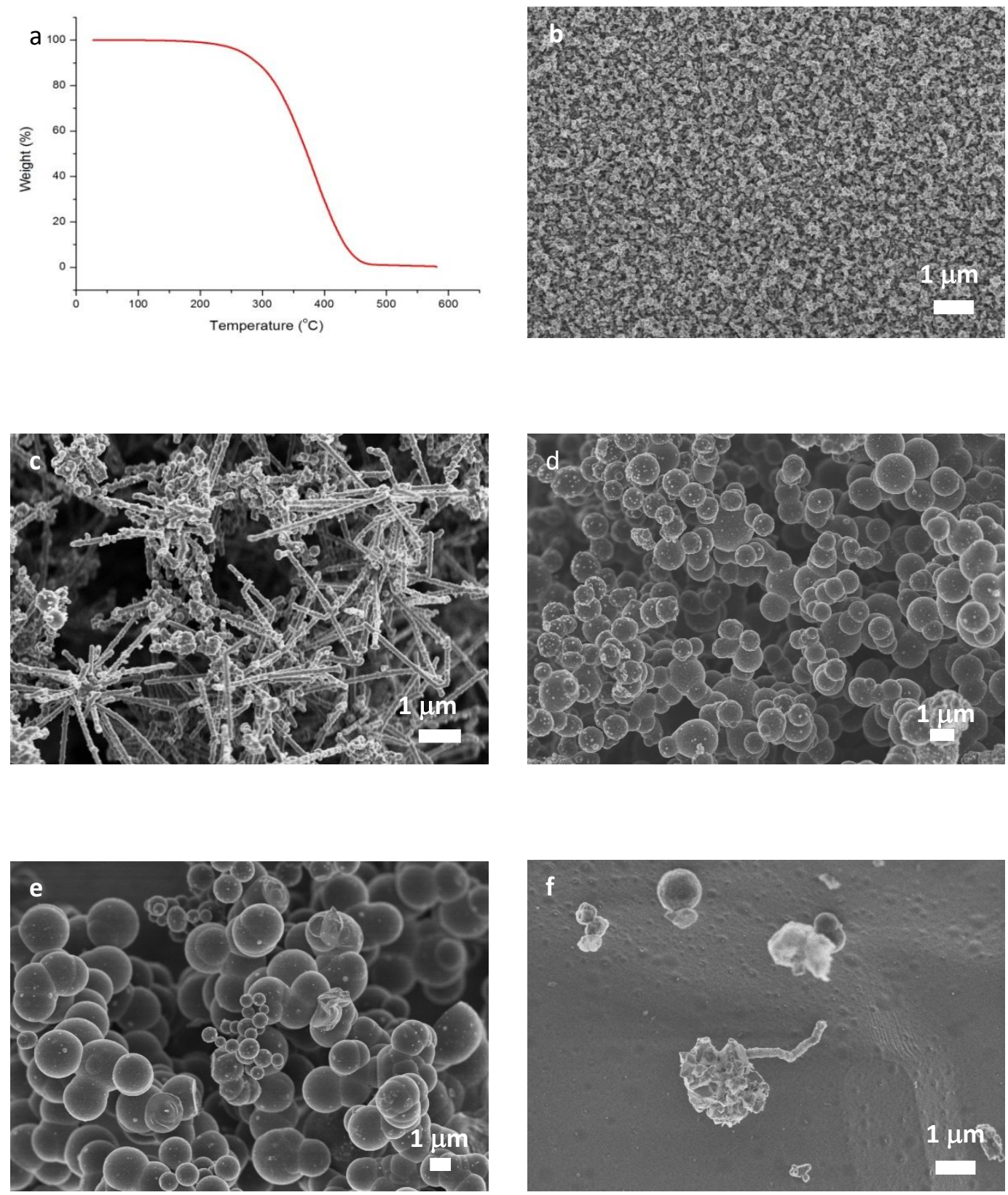

Fig. 1. (a) TGA curve of waste engine oil and FESEM images of CNTs synthesized at different temperature: (b) $600^{\circ} \mathrm{C}$, (b) $700^{\circ} \mathrm{C}$, (c) $800^{\circ} \mathrm{C}$, (d) $900^{\circ} \mathrm{C}$ and (e) $1000^{\circ} \mathrm{C}$

Fig. 2. shows the micro-Raman spectra of carbon-based materials. Two dominant peaks were clearly seen at $\sim 1360$ and $\sim 1590 \mathrm{~cm}^{-1}$ represented $\mathrm{D}$ and $\mathrm{G}$ band peaks which indicate the defect and graphitic structure of carbon structure respectively (Lou, Chen et al. 2006). The ratio of $\mathrm{D}$ and $\mathrm{G}$ bands $\left(I_{D} / I_{G}\right)$ indicates the disorder of carbon structures. Table 2 shows the $\mathrm{D}$ and $\mathrm{G}$ peak positions and $I_{D} / I_{G}$ ratio of carbon materials at different synthesis temperatures. A moderate $I_{D} / I_{G}$ ratio $(0.61)$ at $600^{\circ} \mathrm{C}$ of synthesis temperature indicate a uniform and low deffect of carbon structure although the a-C was produced. This was also confirmed by the FESEM images in Fig. 1(b). Material synthesized at $700^{\circ} \mathrm{C}$ has an $I_{D} / I_{G}$ ratio of 0.67 . Optimized carbon microspheres with diameter of were produced at $800^{\circ} \mathrm{C}$ synthesis temperature since it has a lower $I_{D} / I_{G}$ ratio $(0.79)$ than 
carbon microspheres synthesized at $900^{\circ} \mathrm{C}$. High $I_{D} / I_{G}$ ratio $(0.95)$ at $900^{\circ} \mathrm{C}$ synthesis temperature shows a lower degree of graphitization of carbon microspheres. The most defective structure, confirmed with FESEM images in Fig. 1(f) has the highest $I_{D} / I_{G}$ ratio (0.96) was obtained at high synthesis temperature, $1000^{\circ} \mathrm{C}$.

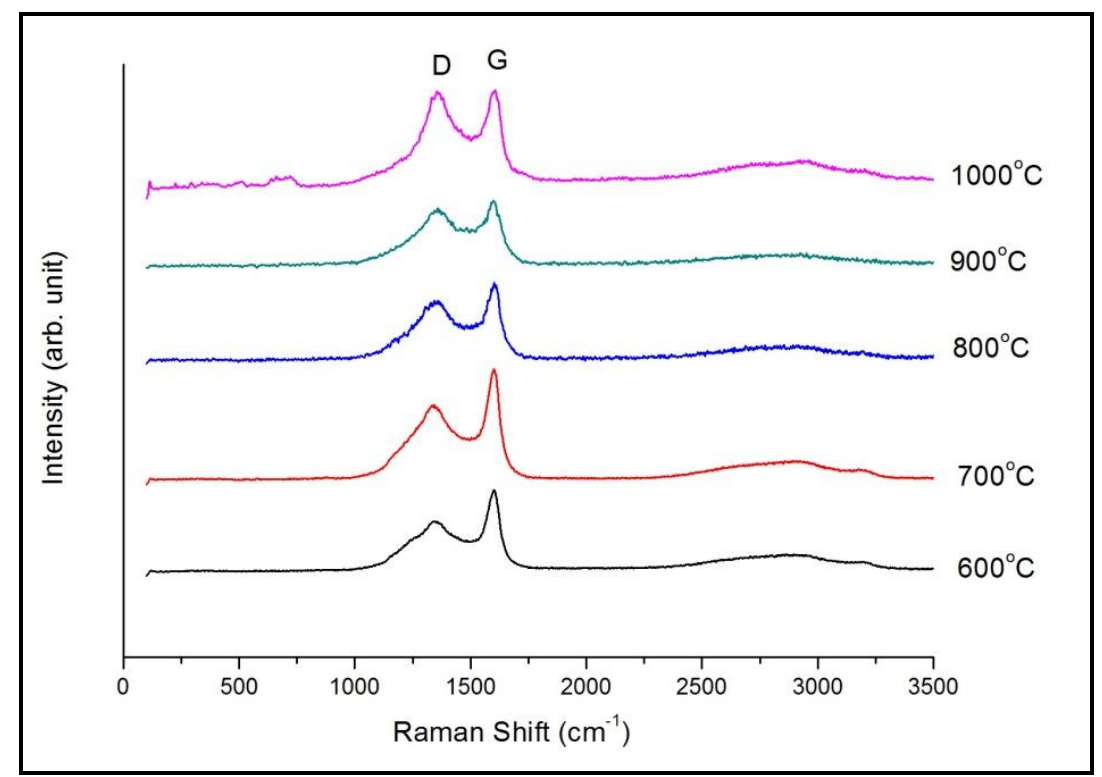

Fig. 2. Micro Raman spectrum of carbon materials synthesized at different temperatures

Table 2: Raman peak position and $I_{D} / I_{G}$ ratio of carbon materials synthesized at different temperatures.

\begin{tabular}{|c|c|c|c|}
\hline $\begin{array}{c}\text { Temperature } \\
\left({ }^{\circ} \mathbf{C}\right)\end{array}$ & $\begin{array}{c}\text { D-peak } \\
\left(\mathbf{c m}^{-\mathbf{1}}\right)\end{array}$ & $\begin{array}{c}\text { G peak } \\
\left(\mathbf{c m}^{-\mathbf{1}}\right)\end{array}$ & $\boldsymbol{I}_{\boldsymbol{D}} / \mathbf{I}_{G}$ ratio \\
\hline 600 & 1359.8 & 1597.3 & 0.61 \\
\hline 700 & 1351.8 & 1596.8 & 0.67 \\
\hline 800 & 1357.7 & 1598.2 & 0.79 \\
\hline 900 & 1368.0 & 1597.5 & 0.95 \\
\hline 1000 & 1370.2 & 1596.8 & 0.96 \\
\hline
\end{tabular}

\section{CONCLUSIONS}

It can be concluded that synthesis temperature has a big role on the growth of carbon materials from WEO especially for their structures. Synthesis temperature also affects the average size of carbon materials. At temperature lower than $700^{\circ} \mathrm{C}$, precursor was not completely decomposed and low catalytic activity caused the amorphous structure of carbon material formed. At $700^{\circ} \mathrm{C}$, a material contained $\mathrm{Cu}$ and $\mathrm{Al}$ nanowires together with carbon microspheres were produced. 
Well growth carbon microspheres were obtained at $800^{\circ} \mathrm{C}$ while at $900^{\circ} \mathrm{C}$, bigger diameter and lower crystallinity of carbon microspheres were produced. At very high temperature, $1000^{\circ} \mathrm{C}$, a high defect of carbon structure was formed.

\section{REFERENCES}

Ajayan, P. M. and O. Z. Zhou (2001). Applications of carbon nanotubes. Carbon Nanotubes, Springer: 391-425.

Alfarisa, S., R. N. Safitri, et al. (2016). "Effect of Catalyst Concentrations on the Growth of Carbon Nanotubes from Waste Engine Oil."

Alfarisa, S. and A. B. Suriani (2016). "Pemanfaatan Minyak Pelumas Bekas untuk Fabrikasi Bola Karbon Mikro menggunakan Metode Deposisi Uap Kimia Termal." Sainmatika: Jurnal Ilmiah Matematika dan Ilmu Pengetahuan Alam 13(1).

Asli, N. A., M. S. Shamsudin, et al. "Field electron emission properties of vertically aligned carbon nanotubes deposited on a nanostructured porous silicon template: The hidden role of the hydrocarbon/catalyst ratio." Microelectronic Engineering 108(0): 86-92.

Cheng, H. M., F. Li, et al. (1998). "Large-scale and low-cost synthesis of single-walled carbon nanotubes by the catalytic pyrolysis of hydrocarbons." Applied Physics Letters 72(25): 3282-3284.

Donev, L. A. K. (2009). Carbon nanotube transistors:

Capacitance measurements, localized damage, and use as gold scaffolding, Cornell University.

Lou, Z., C. Chen, et al. (2006). "Largescale synthesis of carbon spheres by reduction of supercritical $\mathrm{CO}<$ sub $>2</$ sub $>$ with metallic calcium." Chemical physics letters 421(4): 584-588.

Nowack, B., R. M. David, et al. (2013). "Potential release scenarios for carbon nanotubes used in composites." Environment international 59: 1-11.

Poudel, P. and Q. Qiao "Carbon nanostructure counter electrodes for low cost and stable dyesensitized solar cells." Nano Energy(0).

Shanov, V., W. Cho, et al. (2013). "CVD growth, characterization and applications of carbon nanostructured materials." Surface and Coatings Technology 230(0): 77-86.

Suriani, A. B., S. Alfarisa, et al. (2015). "Quasi-aligned Carbon Nanotubes Synthesised from Waste Engine Oil." Materials Letters 139: 220223.

Suriani, A. B., A. R. Dalila, et al. (2013). "Vertically aligned carbon nanotubes synthesized from waste chicken fat." Materials Letters 101(0): 61-64.

Suriani, A. B., R. Md Nor, et al. (2010). "Vertically aligned carbon nanotubes synthesized from waste cooking palm oil." Journal of the Ceramic Society of Japan 118(1382): 963-968. 
Effect of Synthesis Temperature...Jupiter... Vol 1 No 1...Juli 2019...1-6

Suhufa Alfarisa, Suriani Abu Bakar

Wilgosz, K., X. Chen, et al. (2012).

"Template method synthesis of mesoporous carbon spheres and its applications as supercapacitors." Nanoscale research letters 7(1): 1-5.

Zobir, S. A. M., S. Abdullah, et al. "Synthesis of carbon nano- and microspheres using palm olein as the carbon source." Materials Letters 78(0): 205-208. 